\title{
Research Paper: Decision-Making Styles and Attitude Towards Substances: Predictors of Potential Addiction in Adolescents
}

\author{
Khadijeh Fooladvand $^{1 *}$, Ahmad Borjali ${ }^{1}$, Farideh Hosein Sabet ${ }^{1}$, Ali Delavar ${ }^{2}$
}

1. Department of Clinical Psychology, Faculty of Psychology and Educational Sciences, Allameh Tabataba'i University, Tehran, Iran.

2. Department of Assessment and Measurement, Faculty of Psychology and Educational Sciences, Allameh Tabataba'i University, Tehran, Iran.

\begin{tabular}{|c|c|}
\hline $\begin{array}{l}\text { Use your device to scan } \\
\text { and read the article online }\end{array}$ & dtation: Fooladvand, Kh., Borjali, A., Hosein Sabet, F., \& Delavar, A. (2017). Decision-Making Styles and Attitude Towards \\
\hline 口iftivis & $\begin{array}{l}\text { Substances: Predictors of Potential Addiction in Adolescents. Journal of Practice in Clinical Psychology, 5(2), 91-98. https://doi. } \\
\text { org/10.18869/acadpub.jpcp.5.2.91 }\end{array}$ \\
\hline DLingip: & dol': https://doi.org/10.18869/acadpub.jpcp.5.2.91 \\
\hline
\end{tabular}

Article info:

Received: 18 Nov. 2016

Accepted: 06 Feb. 2017
Keywords:

Adolescent, Decision-making, Attitude, Substance-related disorders

\begin{abstract}
Objective: In all societies, adolescents are the most vulnerable age group to addiction. Decision-making styles and attitude toward substances can play an important role in the tendency of adolescents to addiction.

The aim of the current study was to investigate the role of decision-making styles and attitude toward substances in predicting the potential addiction among adolescents.

Methods: In this descriptive study, a total of 546 adolescents participated from different high schools in Lorestan Province, Iran that were selected through multiple cluster sampling method. The participants were asked to complete different questionnaires of demographic characteristics, decision-making styles, attitude toward substance, and potential addiction. The obtained data were analyzed through SPSS 16. The Pearson correlation coefficient and regression analysis were used for determining the relationships between the study variables.

Results: The results of the study indicated that general attitude; beliefs; emotions; readiness for action; avoidant, spontaneous and dependent decision-making styles have significant positive correlations with potential addiction. While potential addiction is correlated negatively with rational and intuitive decision-making styles. Also, the results of regression analysis showed that potential addiction is predictable by the components of the decision-making styles and attitude toward substances. Multiple regression analysis indicated that components of the decision-making styles and attitude toward substances significantly predicted $25.1 \%$ and $20.7 \%$ of the variance of potential addiction, respectively.
\end{abstract}

Conclusion: The results of this study showed that decision-making styles and attitude toward substance can explain a high degree of variability to potential addiction among adolescents. Accordingly, teaching rational decision-making style and negative attitudes to substances may lead to improvements in the prevention and treatment of addiction in adolescents.

* Corresponding Author:

Khadijeh Fooladvand, PhD Student

Address: Department of Clinical Psychology, Faculty of Psychology and Educational Sciences, Allameh Tabataba'i University, Tehran, Iran.

Tel: +98 (66) 32522366

E-mail: kfooladvand@yahoo.com 


\section{Introduction}

ddiction is one of the social problems that has a large negative effect on societies and creates serious psychological, physical, and social problems. Addiction has become widespread in the past few decades (Shaghaghy, Saffarinia, Iranpoor \& Soltanynejad, 2011). Research also indicates that, in all societies, adolescents are the most vulnerable age group to addiction (Amanelahi, Aslani, Mazeri Ebrahimi, \& Darkhor, 2012) and substance use in adolescents has increased (Howlett, Williams, \& Subramaniam, 2012). Also, substance use among Iranian adolescents has increased and it is one of the most common disorders in adolescence (Delawar, Rezaei, \& Alizadeh, 2009). Personal and social consequences of substance use provide a better understanding of risk factors and protective factors related to it (Rhodes, Reddy, \& Grossman, 2005).

Adolescence is the most appropriate period to study decision-making ability. Some of the important decisions such as choosing the educational field and engaging in some risky behaviors that may lead to substance use are made during adolescence. Although adolescence is a critical period in life, there are risky and uncontrolled conditions that lead adolescents to make risky decisions and experience the consequences of these decisions (Akbari, \& Zare, 2012). Clark and Robbins (2002) suggest that, in critical situations, adolescents who have poor decisionmaking skills prefer to rely on substance use instead of using problem solving techniques. So, adolescents who use substances are less rational and use maladaptive strategies for decision-making. Therefore, improving decision-making can protect adolescents when they encounter risk factors of addiction. Decision-making process typically includes evaluation of alternatives in terms of performance (i.e. cost-benefit assessment) (Syngelaki, Moore, Justin, Savage, Fairchild \& Van Goozen, 2009).

Heyman and Dunn (2002) and Vassileva et al. (2007) acknowledged that the person's vulnerability to addiction is due to differences in decision-making styles. Therefore, addicts, compared with non-addicts, decide less rationally. Also, Bechara and Damasio (2002), Bechara, Dolan, and Hindes (2002), Redish, Jensen and Johnson (2008) believed that addicts have less sensitivity to the negative consequences of their decisions, pay more attention to the immediate results of their decisions and have more problems in decision-making.

Evidence also suggests that substance use depends on positive attitudes toward substance. Attitude is a relatively constant method in thought, feeling, and behavior toward individuals, groups, and events (Torkan \& Kajbaf, 2008). Accordingly, attitude toward substance includes three elements that play an important role in the onset of substance use: cognitive, emotional, and behavioral. Bandura suggests that substance use behavior is associated with positive attitudes and beliefs toward substance. He considers positive attitudes toward substance as a precursor for substance use behaviors (Rahmati \& Etemadi, 2006). Ellis (2001) (cited in Bahrami, Moazedian \& Hoseini Almadani, 2013) also believed that positive attitudes lead to recurrence in addicts. In addition, cognitive bias theory suggests that the onset of substance use is bias in attitudes. Moreover, theory of planned behavior proposes that certain substance-attitudes are a function of both the personal expectations (i.e. costs and benefits) that adolescents expect from substance use, and the affective values that they place on those consequences (Petraitis, Flay, \& Miller, 1995; West, 2006). Studies also show that individuals who have positive attitudes to substance use, are more likely to engage in substance use (Center for Substance Abuse Prevention, 2001; Botvin \& Griffin, 2004).

The increasing tendency of adolescents for substance use is very disturbing (Mohamadkhani, 2007). Ignoring the substance use problem leads to the harmful consequences such as the destruction of social and economic resources (Rezaei, Delawar, \& Najafi, 2012). Thus, research on identifying risk factors of this problem will be beneficial in promoting the welfare and well-being of adolescents. The review of the studies in the potential addiction among adolescents has made it clear the research gap in understanding factors that can contribute to substance use in Iranian adolescents. Because studies have not directly examined this issue in Iran, this study is unique and has its own innovations in terms of results explanation. Regarding the above-mentioned issues, the aims of this study include 1) determining the role of decision-making styles on adolescents' potential addiction 2) determining the role of attitude toward substance on adolescents' potential addiction.

\section{Methods}

In the current study, a cross sectional design was used. The study population consisted of high school adolescents (girls and boys) in the province of Lorestan. They were studying in four grades of high school: first, second, third, and fourth. According to Stevens (1996) (cited in Hooman, 2005), taking at least 15 subjects for each predictor variable in the multiple regression analysis is a good rule of thumb. In this study, there were 9 predictor variables; thus, minimum sample size should 
be 135 participants. The sampling method used in the study was a multistage random sampling method. In the first stage, Khorramabad and Selseleh cities were randomly selected out of Lorestan cities. In the second stage, 6 high schools were randomly selected out of high schools of these cities. Finally, in the third stage, a random sampling of schools with 32 classes (546 students) was selected for the study sample. Inclusion criteria for the study participants were their presence at school at the time of the study and their willingness to participate in the study. Also, exclusion criteria of the current study were failure to complete the questionnaires and lack of interest to participate in the study. After obtaining the permission from Lorestan Education Office, the researcher referred to schools and asked high school students to complete the questionnaires of this study. The participants were advised that participation in the study is voluntary for all persons, their names are not required, and the obtained data will be analyzed only as a group. The approximate duration to fill out the questionnaires was 35 minutes. The data gathering tools in this study included the following questionnaires that were completed through self-report method by subjects.

Demographic characteristics questionnaire: This questionnaire included data about age, gender, high school name, educational grade, city, adolescents' substance use history, their friend's substance use history and their parents' substance use history.

Iranian Addiction Potential Scale: The Iranian addiction potential questionnaire was designed with respect to the mental-social state of Iranian society by Zargar (2006 as cited in Hajihasani, Shafi Abadi, Pirsaghi \& Kiyanipour, 2012). The questionnaire includes two factors, 36 questions, and 5 lie-detector questions. In the first factor (active readiness), most questions are related to antisocial behavior, craving, and sensation seeking; and in the second factor (passive readiness), most questions are related to lack of assertiveness. The questionnaire is scored on a Likert-type scale ranging from 0 (completely disagree) to 3 (strongly agree). Examples of questions in this scale include "Friendship with people who use substance is no problem" and "substance has beneficial effects". Two methods were used for evaluating the validity of the scale. Regarding the criterion validity, addiction potential questionnaire distinguished addicted and non-addicted group as well. The validity of the scale was calculated through its correlation with symptom checklist 25 ( $\mathrm{r}=0.45, \mathrm{P}<0.0001)$ (Hajihasani, Shafi Abadi, Pirsaghi, \& Kiyanipour, 2012). In addition, Haji Hassani et al. (2012) obtained a reliability index of 0.87 for the questionnaire using the Cronbach $\alpha$ method. In the pres- ent study, the Cronbach $\alpha$ values for the addiction potential questionnaire, as well as active and passive factors were obtained $0.87,0.85$ and 0.74 , respectively.

Decision-making Styles Scale: Scott and Bruce (1995 as cited in Tabesh \& Zare, 2013), designed decision-making styles questionnaire for the assessment of decision-making styles using factor analysis. This questionnaire has 25 questions that measures rational, intuitive, avoidant, dependent and spontaneous decision making styles. The questionnaire is rated based on a Likert-type scale ranging from 0 (completely disagree) to 4 (strongly agree). Each decision-making style includes 5 questions (Tabesh \& Zare, 2013). Examples of questions in this scale are as follows: "I am able to make decisions without consulting with others" and "I make decisions that I feel correct".

Content validity of the questionnaire was confirmed by experts and its construct validity has been analyzed through calculating correlation between decision-making styles and also correlation between scores of each question with scores of each style (Hadizadeh Moghadam, 2008 cited in Tabesh \& Zare, 2013). The Cronbach $\alpha$ values for the decision-making styles has been reported 0.68 to 0.94 (Tabesh \& Zare, 2013). In the present study, the Cronbach $\alpha$ for the decision-making styles questionnaire was 0.84 and the Cronbach $\alpha$ values for rational, intuitive, avoidant, dependent and spontaneous decision-making styles were obtained $0.66,0.67,0.79,0.62$ and 0.79 , respectively.

Attitude toward Substance Scale: The questionnaire was developed by Rahmati (2004 as cited in Sohrabi \& Khalili, 2011) and has 34 questions in which respondents express views about every question with 3 options. The questionnaire is scored on a Likert-type scale ranging from 0 (completely disagree) to 3 (strongly agree). Example of questions in this scale include "In my opinion, the majority of adolescents and young people who are addicted to substances... A) to advise and encourage by substance dealers, B) to start among their friends, C) to learn from their parents and relatives". The results of the factor analysis of questions by Rahmati showed that this scale has been saturated from general attitudes, beliefs (cognitive), emotional (affective) and readiness for action (behavior) (Sohrabi \& Khalili, 2011). To obtain questionnaire validity, it was sent by Sohrabi and Khalili Sadrabad to 5 professors to examine its face and content validity. The reliability of the questionnaire was calculated through test-retest and Cronbach $\alpha$ test. Reliability coefficients were obtained 0.71 by test-retest and 0.85 through Cronbach $\alpha$ (Sohrabi \& Khalili, 2011). In the present study, the Cronbach $\alpha$ was calculated for total questionnaires as 0.87 and the indexes obtained for general attitudes, beliefs (cognitive), emotional (affective), and 
readiness for action (behavior) were $0.77,0.70,0.66$, and $0.67)$ respectively. In the current study, Pearson correlation and regression analysis were used for data analyses. The obtained data were analyzed using SPSS 16 and the level of significance was considered at $\mathrm{P}<0.05$.

\section{Results}

The present study was a cross sectional one and was conducted on 546 adolescents (278 girls, 268 boys) in 2014. The participants were at different educational grades. About $42.7 \%$ were in the first grade, $34.1 \%$ in the second grade, $16.5 \%$ in the third grade, and $4.2 \%$ in the fourth grade. Also, $4.4 \%$ of adolescents did not mention their grades. Regarding the history of substance use, they reported that $93.4 \%$ of adolescents, $88.5 \%$ of their friends, and $91.2 \%$ of their parents had no history of substance use. In addition, the reported history of substance use among adolescents, their friends, and parents were $1.1 \%, 6.2 \%$, and $3 \%$, respectively. Results of mean, standard deviation and correlations of predictor variables with potential addiction are presented in Table 1.

As can be seen in Table 1, rational and intuitive decision-making styles have significant negative correlations with potential addiction, respectively $(\mathrm{P}<0.01, \mathrm{r}=-0.38$; $\mathrm{P}<0.01, \mathrm{r}=-0.23$ ); while dependent, avoidant and spontaneous decision-making styles have significant positive correlation with the potential addiction $(\mathrm{P}<0.05, \mathrm{r}=0.10$; $\mathrm{P}<0.01, \mathrm{r}=0.35 ; \mathrm{P}<0.01, \mathrm{r}=0.27$; respectively). Also, general attitude, belief, emotion and readiness for action have significant positive correlation with the potential addiction $(\mathrm{P}<0.01, \mathrm{r}=0.36 ; \mathrm{P}<0.01, \mathrm{r}=0.41 ; \mathrm{P}<0.01$, $\mathrm{r}=0.40 ; \mathrm{P}<0.01, \mathrm{r}=0.29$; respectively).
The results of stepwise multiple regression analysis (Table 2) showed that rational decision-making style with a regression coefficient ( 0.377 ) was entered to the regression equation and significantly was able to predict $14.2 \%$ of potential addiction variance $(\mathrm{P}<0.0001)$. In the second step, avoidant decision-making style was added to the equation and the regression coefficient has increased to 0.48 . Avoidant decision-making style, alone, significantly explained $8 \%$ of the potential addiction variance $(\mathrm{P}<0.0001)$. In the third step, by adding the spontaneous decision-making style, the regression coefficient has increased to 0.491 and spontaneous decision-making style explained $1.1 \%$ of the potential addiction variance $(\mathrm{P}<0.005)$.

In the fourth step, dependent decision-making style was added to the equation and the regression coefficient increased to 0.499 . The dependent decision-making style explained $0.8 \%$ of the potential addiction variance $(\mathrm{P}<0.01)$. Finally, in the fifth step, by adding the intuitive decision-making style, the regression coefficient was increased to 0.508 and intuitive decision-making style explained $0.9 \%$ of potential addiction variance $(\mathrm{P}<0.01)$. Overall, rational, avoidance, spontaneous, dependent and intuitive decision-making styles were able to anticipate $25.1 \%$ of the adolescents' potential addiction. The Watson coefficient (1.69) was ranging from 1.5-2.5, which represents compliance with an assumption of errors independence (Palant, 2011).

As can be seen in Table 3, equation coefficients based on raw scores and standard scores were statistically significant and have the predictive power for adolescents' potential addiction. On the other hand, the coefficients of VIF are less than 1.81 which indicates the lack of strong colinear-

Table 1. Mean, standard deviation, and correlation between predictor variables with potential addiction $(n=546)$

\begin{tabular}{cccc}
\hline Variable & Mean & Standard Deviation & Correlation With Potential Addiction \\
\hline Rational decision-making style & 11.77 & 3.49 & $-0.38^{* *}$ \\
Intuitive decision-making style & 11.73 & 3.48 & $-0.23^{* *}$ \\
Dependent decision-making style & 8.70 & 3.04 & $0.10^{*}$ \\
Avoidant decision-making style & 8.01 & 4.08 & $0.35^{* *}$ \\
\hline Spontaneous decision-making style & 7.99 & 3.90 & $0.27^{* *}$ \\
General attitude & 4.11 & 3.47 & $0.36^{* *}$ \\
Belief & 3.08 & 2.75 & $0.41^{* *}$ \\
Emotion & 5.49 & 3.60 & $0.40^{* *}$ \\
Readiness for action & 5.43 & 3.18 & $0.29^{* *}$ \\
\hline
\end{tabular}

$* \mathrm{P}<0.05 * * \mathrm{P}<0.01$

CLINICAL PSYCH $\oplus$ LOGY 
Table 2. Summary of decision-making styles' regression analysis model to predict potential addiction

\begin{tabular}{|c|c|c|c|c|c|c|c|c|}
\hline Step & Predictors & $\mathbf{R}$ & $\mathbf{R}^{\mathbf{2}}$ & $\begin{array}{l}\text { Adjusted } \\
\mathbf{R}^{2}\end{array}$ & $\begin{array}{c}\mathbf{R}^{2} \\
\text { Change }\end{array}$ & df & $\begin{array}{l}\text { Sig. } \mathbf{F} \\
\text { Change }\end{array}$ & $\begin{array}{l}\text { Durbin } \\
\text { Watson }\end{array}$ \\
\hline 1 & Rational & 0.377 & 0.142 & 0.140 & 0.142 & 544 & 0.0001 & 1.69 \\
\hline 2 & Rational+Avoidant & 0.48 & 0.230 & 0.227 & 0.088 & 543 & 0.0001 & \\
\hline 3 & Rational+Avoidant+Spontaneous & 0.491 & 0.241 & 0.237 & 0.011 & 542 & 0.005 & \\
\hline 4 & $\begin{array}{l}\text { Rational+Avoidant+Spontaneous+De } \\
\text { pendent }\end{array}$ & 0.499 & 0.249 & 0.243 & 0.008 & 541 & 0.01 & \\
\hline 5 & $\begin{array}{l}\text { Rational+Avoidant+Spontaneous+Depe } \\
\text { ndent+Intuitive }\end{array}$ & 0.508 & 0.258 & 0.251 & 0.009 & 540 & 0.01 & \\
\hline
\end{tabular}

Table 3. Raw and standardized coefficients of decision-making styles regression equation to predict potential addiction

\begin{tabular}{cccccccc}
\hline Variable & B & $\begin{array}{c}\text { Std. Error the } \\
\text { Estimate }\end{array}$ & Beta & T & Sig. & Tolerance & VIF \\
\hline Rational & -1.20 & 0.17 & -0.31 & -7.13 & 0.0001 & 0.71 & 1.41 \\
Avoidant & 0.53 & 0.16 & 0.16 & 3.25 & 0.001 & 0.55 & 1.80 \\
\hline Spontaneous & 0.56 & 0.16 & 0.16 & 3.49 & 0.001 & 0.62 & 1.62 \\
\hline Dependent & 0.52 & 0.19 & 0.12 & 2.81 & 0.005 & 0.79 & 1.27 \\
\hline Intuitive & -0.44 & 0.17 & -0.11 & -2.55 & 0.01 & 0.67 & 1.48 \\
\hline
\end{tabular}

PRACTICE in
CLINICAL PSYCH $P$ LOGY

ity relations between the independent variables. The coefficients of VIF should be less than 10 (Mansorfar, 2007).

As can be seen in Table 4, in the first step, belief, with a regression coefficient $(0.406)$ was entered to the regression equation and significantly was able to predict $16.5 \%$ of potential addiction variance $(\mathrm{P}<0.0001)$. In the second step, emotion was added to the equation and the regression coefficient has increased to 0.435 . Emotion, alone, significantly explained $2.5 \%$ of the potential addiction variance $(\mathrm{P}<0.0001)$. In the third step, by adding the readiness for action, the regression coefficient was increased to 0.454 and readiness for action explained $1.7 \%$ of the potential addiction variance $(\mathrm{P}<0.001)$. Overall, belief, emotion and readiness for action were able to anticipate $20.7 \%$ of the adolescents' potential addiction. The Watson coefficient (1.76) ranged from 1.5 to 2.5 , which represents compliance with an assumption of errors independence (Palant, 2011).

As can be seen in Table 5, equation coefficients based on raw scores and standard scores were statistically significant and have the predictive power for adolescents' potential addiction.

\section{Discussion}

This study aimed to predict potential addiction through decision-making styles and attitude toward substances. The results showed that components of the decision-

Table 4. Summary of attitude toward substance' regression analysis model to predict potential addiction

\begin{tabular}{ccccccccc}
\hline Step & Predictors & $\mathbf{R}$ & $\mathbf{R}^{\mathbf{2}}$ & $\begin{array}{c}\text { Adjusted } \\
\mathbf{R}^{\mathbf{2}}\end{array}$ & $\begin{array}{c}\mathbf{R}^{\mathbf{2}} \\
\text { Change }\end{array}$ & $\begin{array}{c}\text { Sig.F } \\
\text { Change } \\
\text { Watson }\end{array}$ \\
\hline 1 & Belief & 0.406 & 0.165 & 0.163 & 0.165 & 544 & 0.0001 & 1.76 \\
2 & Belief+Emotion & 0.435 & 0.190 & 0.187 & 0.025 & 543 & 0.0001 \\
3 & $\begin{array}{c}\text { Belief+Emotion+Readiness for } \\
\text { action }\end{array}$ & 0.454 & 0.207 & 0.202 & 0.017 & 542 & 0.001 \\
\hline
\end{tabular}


Table 5. Raw and standardized coefficients of attitude to substance regression equation to predict potential addiction

\begin{tabular}{cccccccc}
\hline Variable & B & $\begin{array}{c}\text { Std. Error the } \\
\text { estimate }\end{array}$ & Beta & T & Sig. & Tolerance & VIF \\
\hline Belief & 1.01 & 0.28 & 0.20 & 3.58 & 0.0001 & 0.46 & 2.19 \\
Emotion & 0.79 & 0.21 & 0.21 & 3.69 & 0.0001 & 0.47 & 2.13 \\
Readiness for action & 0.63 & 0.19 & 0.14 & 3.40 & 0.001 & 0.84 & 1.18 \\
\hline & & & & & & & PLACTICE in \\
CLICAL PSCH & & & & &
\end{tabular}

making styles (rational, intuitive, avoidant, dependent and spontaneous) can be significant predictors of potential addiction. Also, rational and intuitive decisionmaking styles have significant negative relationships with potential addiction while the avoidant, dependent, and spontaneous decision-making styles have significant positive relationships with potential addiction. The findings are consistent with previous studies (Heyman and Dunn, 2002; Vassileva et al., 2007; Bechara and Damasio, 2002; Bechara et al., 2002; Redish et al., 2008).

To explain these findings, it can be said that adolescents who have weak decision-making skills prefer to rely on substance use instead of using problem solving techniques. Thus, adolescents who use substance are less rational and use maladaptive strategies for decisionmaking (Clark \& Robbins, 2002). Heyman and Dunn (2002) and Vassileva et al. (2007) acknowledged that the person's vulnerability to addiction is due to differences in decision-making styles. Therefore, addicts, compared with non-addicts, decide less rationally. Also, addicts have less sensitivity to negative consequences of their decisions, pay more attention to the immediate results of their decisions, and have more problems in decisionmaking (Bechara and Damasio, 2002; Bechara, Dolan, and Hindes, 2002; Redish et al., 2008).

Addicts do not try enough for obtaining information and careful assessment before decision-making. Accordingly, recognizing the problem, assessing the situation and considering the goals, searching options, choosing the best option for the operation, performing of the decision and evaluating the results are important for efficient and rational decision-making and can reduce adolescents' tendency towards addiction. Adolescents, who do not have ability to cope with the demands and pressures of the environment, especially peers, may take avoidant, spontaneous and dependent decisions and may engage in risky behaviors such as addiction.

Also, components of the attitude toward substance (general attitude, beliefs, emotions, and readiness for action) significantly predict potential addiction among adolescent. In addition, general attitude, beliefs, emotions and readiness for action have positive correlation with potential addiction. The findings are consistent with previous studies (Center for Substance Abuse Prevention, 2001; Botvin \& Griffin, 2004).

To explain these findings, theories of Bandura (1973 as cited in West, 2005), Ellis (2001 as cited in Bahrami, Moazedian \& Hoseini Almadani, 2013), cognitive biases and planned behavior (Petraitis et al., 1995; West, 2006) can be proposed. Bandura suggests that substance use behavior is associated with positive attitudes and beliefs toward substance. He considered positive attitudes toward substance as a precursor for substance use behaviors (Rahmati \& Etemadi, 2006). Ellis (2001) (cited in Bahrami et al., 2013) also believed that positive attitudes lead to recurrence in addicts. In addition, Cognitive Bias Theories propose that it is biased in attitudes linked to these beliefs that are at the root of the problem of addiction. Moreover, Theory of planned behavior proposes that certain substanceattitudes are a function of both the personal expectations (i.e. costs and benefits) that adolescents expect from substance use, and the affective values that they place on those consequences (Petraitis et al., 1995; West, 2006).

Attitude can be a research predictor because attitude has cognitive (belief), affective (emotion) and behavioral (readiness for action) factors and strong beliefs and with great emotional burden to a topic or against it to be able in predicting the approach and avoidance behaviors (Bahrami et al., 2013). So, one of the main reasons for substance use among adolescents is the risk of a positive attitude to the substance and its effects. Also, the tendency to substance use has increased in the mistaken attitude that "occasional and recreational consumption does not lead to addiction". Now, having such attitudes among adolescents cause the tendency towards and increase in substance use in this group.

According to the study results, it became clear that $1.1 \%$ of adolescents, $2.6 \%$ of their parents, and $3 \%$ of 
their friends have used substances. According to social cognitive theory, adolescents decide about the substance use based on the two information groups of the parents and peers (Akers \& Sellers, 2004). If parents and friends of adolescents use substance, it is likely that they mimic their behavior and consume substances. Adolescents become acquainted with the substance and encouraged to use substances by peers (Bahr, Hoffmann, \& Yang, 2005). Very few adolescents who their friends did not use substances, go to the substance use (Palmqvist \& Santavirta, 2006; Ahlstrom, 2002). Relationships with peers, who are oblivious to the social norms of substance use, not only increase access to substance, but also provide an environment that has values and beliefs consistent with the substance use. In addition, when parents, especially same-sex parents use substances, adolescents will likely to use substances; because, parents are important role models for adolescents and an important source of norms-acquisition related to substance use for adolescent (Elliott-Erickson, Lane, \& Ranson, 2009).

Furthermore, this study had some limitations. First, the study population included only adolescents in Lorestan Province. Hence, the results of the study might not be generalizable to adolescents in other provinces due to cultural differences. Second, although the results of this study indicate that decision-making styles and attitudes toward substance play a significant role in predicting potential addiction; these results do not mean that these variables are the only explanatory factors for potential addiction in adolescents.

Accordingly, due to the limitations of this study, it is suggested that researchers in future studies examine samples of adolescents in other provinces of Iran. Then, they compare their research findings with this research to clarify whether cultural differences can lead to different outcomes for adolescents in other provinces. Also, addiction is caused by the interaction of several factors such as environmental, social, and individual. Therefore, it is proposed that, to enhance the accuracy and effectiveness of addiction prevention and treatment programs, future studies may also investigate the contribution of other variables. At the theoretical level, the findings of this study can help enrich current theories of decision-making styles and attitudes toward substance. Also, it is recommended that substance use interventions focus on these variables. Therefore, training on and promoting rational decisionmaking style and reducing maladaptive decision-making style can protect adolescents who are at risk of addiction. Furthermore, identifying the positive attitudes to substance and turning the positive attitudes to negative attitudes towards substance use can be an important step in the prevention of substance use among adolescents. This study requires replication and experimental confirmations because of its novelty in Iranian cases. Until then, the findings should be interpreted with caution.

In summary, the findings of this study showed that adolescents' decision-making styles and attitudes toward substances influence the potential addiction in adolescents. The growing attention to addiction in adolescents suggests the need to investigate all aspects of decisionmaking styles and attitudes toward substance as variables affecting potential addiction in adolescents. Teaching rational decision-making styles and negative attitudes to substances may lead to improvements in the prevention and treatment of addiction among adolescents.

\section{Acknowledgments}

This article is adapted from the $\mathrm{PhD}$ thesis of the first author. The authors would like to acknowledge the high school adolescents in Lorestan who participated as subjects in this study.

\section{Conflict of Interest}

The authors declared no conflicts of interest.

\section{References}

Ahlstrom, S. (2002). Family practices and adolescent use of legal and illegal drugs: A review. Nordisk Alkohol E Narkotikatidskrift, 19, 76-82.

Akbari, M., \& Zare, H. (2012). [Prediction of risky behavior in adolescence and its relationship with sensation seeking and decision making styles (Persian)]. Journal of Research in Psychological Health, 6(1), 57-65.

Akers, R. L., \& Sellers, C. S. (2004). Criminological theories: Introduction, evaluation, and application ( $4^{\text {th }}$ Ed.). Los Angeles: Roxbury.

Amanelahi, A., Aslani, K. H., Mazeri Ebrahimi, N., \& Darkhor, F. (2012). [A study of relationship between family function and personality characteristics with addiction potential (Persian)]. Journal of Applied Counseling, 3(1), 63-76.

Bahr, S. J., Hoffmann, J. P., \& Yang, X. (2005). Parental and peer influences on the risk of adolescent drug use. The Journal of Primary Prevention, 26(6), 529-551. doi: 10.1007/s10935-0050014-8

Bahrami, F., Moazedian, A., \& Hoseini Almadani, S. A. (2013) [The effectiveness of the training of problem-solving and decision-making skills on the reduction of addicts' positive attitudes to narcotics (Persian)]. Quarterly Journal of Research on Addiction, 7 (25), 57-72. 
Bechara, A., \& Damasio, H. (2002). Decision-making and addiction (part I): Impaired activation of somatic states in substance dependent individuals when pondering decisions with negative future consequences. Neuropsychologia, 40(10), 1675-1689. doi: 10.1016/s0028-3932(02)00015-5

Bechara, A., Dolan, S., \& Hindes, A. (2002). Decision-making and addiction (part II): Myopia for the future or hypersensitivity to reward? Neuropsychologia, 40(10), 1690-1705. doi: 10.1016/s0028-3932(02)00016-7

Botvin, G. J., \& Griffin, K. W. (2004). Life skills training: empirical findings and future directions. The Journal of Primary Prevention, 25(2), 211-232. doi: 10.1023/b:jopp.0000042391.58573.5b

Center for Substance Abuse Prevention. (2001). Science-Based Substance Abuse Prevention: A guide. Maryland, Rockville: Center for Substance Abuse Prevention.

Clark, L., \& Robbins, T. W. (2002). Decision-making deficits in drug addiction. Trends in Cognitive Sciences, 6(9), 361-363. doi: 10.1016/s1364-6613(02)01960-5

Delawar, A., Rezaei, A., \& Alizadeh, A. (2009). [The relationship between family factors and secondary school students attitude towards drug abuse (in Tehran) (Persian)]. Daneshvar Raftar, 1(37), 21-34.

Elliott-Erickson, S., Lane, J., \& Ranson, K. (2009). An overview of risk and protective factors for adolescent substance use and gambling activity: The Alberta youth experience survey 2002. Alberta: Alberta Alcohol and Drug Abuse Commission.

Hajihasani, M., Shafi Abadi, A., Pirsaghi, F., \& Kiyanipour, O. (2012). [Relationship between aggression, assertiveness, depression and addiction potential in female students of $\mathrm{Al}$ lameh Tabbatabai (Persian)]. Knowledge \& Research in Applied Psychology, 13 (3), 65-74.

Heyman, G. M., \& Dunn, B. (2002). Decision biases and persistent illicit drug use: An experimental study of distributed choice and addiction. Drug and Alcohol Dependence, 67(2), 193-203. doi: 10.1016/s0376-8716(02)00071-6

Hooman, H. A. (2005). [Structural equation modeling with Lisrel application (Persian)]. Tehran: Samt Publications.

Howlett, K. D., Williams, T., \& Subramaniam, G. (2012). Understanding and treating adolescent substance abuse: A preliminary review. Focus, 10(3), 293-299. doi: 10.1176/appi. focus.10.3.293

Mansorfar, K. (2007). [Advanced Statistical Methods with Computer Software (Persian)]. Tehran: Tehran University Publications.

Mohamadkhani, S. H. (2007). [Structural model of alcohol, tobacco and other drugs among at risk adolescents: Direct and indirect impact of social and personal factors (Persian)]. Research in Psychological Health, 1(2), 5-16.

Palant, C. H. (2011). Analysis of Behavioral Sciences Data with SPSS. [A. Rezaei Persian trans] Tabriz: Foruzesh Publications.

Palmqvist, R., \& Santavirta, N. (2006). What friends are for: The relationships between body image, substance use, and peer influence among Finnish adolescents. Journal of Youth and Adolescence, 35(2), 192-206. doi: 10.1007/s10964-005-9017-2

Petraitis, J., Flay, B. R., \& Miller, T. Q. (1995). Reviewing theories of adolescent substance use: Organizing pieces in the puz- zle. Psychological Bulletin, 117(1), 67-86. doi: 10.1037/00332909.117.1.67

Rahmati, A., \& Etemadi, A. (2006). [The effect of teaching coping skills on the students attitudes towards drug abuse - using group discussion (Persian)]. Modern Psychological Research, $1(4), 117-141$

Redish, A. D., Jensen, S., \& Johnson, A. (2008). A unified framework for addiction: Vulnerabilities in the decision process. Behavioral and Brain Sciences, 31(04). doi: 10.1017/ s0140525x0800472x

Rezaei, A. M., Delawar, A., \& Najafi, M. (2012). [The construction and validation of opium attitude questionnaire among guidance and high school students (Persian)]. Quarterly Journal of Research on Addiction, 6(24), 37-54.

Rhodes, J. E., Reddy, R., \& Grossman, J. B. (2005). The protective influence of mentoring on adolescents' substance use: direct and indirect pathways. Applied Developmental Science, 9(1), 31-47. doi: 10.1207/s1532480xads0901_4

Shaghaghy, F., Saffarinia, M., Iranpoor, M., \& Soltanynejad, A. (2011). The relationship of decision-making styles and attributional styles in addicted and Non-addicted Men. Addiction $\mathcal{E}$ Health, 3(3-4), 99-104. PMID: 24494123

Sohrabi, F., \& Khalili, A. (2011). [The effectiveness of critical thinking skill training on attitude towards substance abuse (Persian)]. Modern Psychological Research, 6(23), 100-115.

Syngelaki, E. M., Moore, S. C., Savage, J. C., Fairchild, G., \& Van Goozen, S. H. M. (2009). Executive functioning and risky decision making in young male offenders. Criminal Justice and Behavior, 36(11), 1213-1227. doi: 10.1177/0093854809343095

Tabesh, F., \& Zare, H. (2013). [The effect of training emotional intelligence skills on rational, intuitive, avoidant, dependent and spontaneous decision-making styles (Persian)]. Journal of Behavioral Science, 6(4), 323-329.

Torkan, H., \& Kajbaf, M. B. (2008). [What is an Attitude? (Persian)]. Quarterly of Behavioral Sciences Development, 1(1), 49-54.

Vassileva, J., Petkova, P., Georgiev, S., Martin, E. M., Tersiyski, R., Raycheva, M., et al. (2007). Impaired decision-making in psychopathic heroin addicts. Drug and Alcohol Dependence, 86(2-3), 287-289. doi: 10.1016/j.drugalcdep.2006.06.015

West, R. (2006). Theory of addiction. Hoboken, New Jersey: Blackwell Publishing Ltd. 